\title{
The loudness of repeated impact sound (A study on the loudness of impact sound. IV)
}

\author{
Masazumi Kumagai,* Yōiti Suzuki, ** and Toshio Sone** \\ * Sendai Radio Technical College, \\ Miyagi-cho, Miyagi, 989-31 Japan \\ **Research Institute of Electrical Communication, \\ Tohoku University, \\ Katahira, Sendai, 980 Japan
}

(Received 8 March 1982)

\begin{abstract}
The effect of repetition of impact sound on its loudness is investigated. The stimuli used in this experiment are the repeated model impact sounds which have triangular envelope after the actual impact sounds, and they are synthesized by amplitude modulation of sinusoidal carrier. The stimulus is repeated $1,2,4$, or 8 times with the interval of 100,200 , or $400 \mathrm{~ms}$. As the results of this experiment, PSE for loudness of repeated impact sound increases by about $1 \mathrm{~dB}$ for doubling of the number of repetition, and it shows a tendency of saturation along with the increase in the number of repetition. PSE for loudness corresponds to a lesser degree to the energy principle, since doubling of the number of repetition means $3 \mathrm{~dB}$ increase of sound energy. The readings of SPL, measured by a sound level meter with a square circuit of $125 \mathrm{~ms}$ rise time constant and $200 \sim 300 \mathrm{~ms}$ decay time constant, may well describe the loudness of repeated impact sound.
\end{abstract}

PACS number: 43. 50. Cb, 43. 66. $\mathrm{Cb}, 43.85$. Fm

\section{INTRODUCTION}

We carried out some psycho-acoustical experiments on loudness of impact sound. In the experiment, the model impact sound determined on the basis of the real impact sound we encountered in our daily life was used as the test stimulus. As the results of these experiments, the sound pressure level measured through a square circuit with time constant of $125 \mathrm{~ms}$ (equivalent to "fast" response of a sound level meter) was found to be indicative of the loudness of impact sound as in the quasisteady sounds with relatively long duration. And the mean of the sound pressure levels observed through a circuit with $125 \mathrm{~ms}$ time constant and the one through a circuit of $5 \mathrm{~ms}$ time constant, well describes the loudness of impact sound even if its duration is very short. ${ }^{1-3)}$

These results were obtained from experiments with a single burst of impact sound. As for the actual impact sounds appearing in our daily life, there are many kinds of single event impact sound such as the sound from dropping of something, banging of a door and starter's pistols, etc. On the other hand, the sounds from diesel pile hammer, hammering of a nail, playing a rattle and so on are the repeated impact sounds.

The loudness of repeated impact sound was investigated by Garner, ${ }^{4)}$ Garrett, ${ }^{5)}$ Carter $^{6,7)}$ and others. Those studies used the periodic intermittent tone pulses over the range of $0.3 \sim 5 \mathrm{pps}$ to $50 \sim 256 \mathrm{pps}$, and those stimuli differ considerably from a series of distinguishable burst of impact sound used in our experiment.

This study investigated the loudness of repeated impact sounds where a burst of model impact sound from 1 to several repetition, designed after the actual impact sounds, is used as the test stimulus, and the 
increment of loudness due to the number of repetition is examined.

\section{PSYCHO-ACOUSTICAL EXPERIMENT ON LOUDNESS OF IMPACT SOUNDS}

\subsection{Method}

In order to determine the PSE (the point of subjective equality) for loudness of repeated model impact sound, the method of adjustment was used.

Figure 1 shows the envelope of test stimulus for the experiment. The rise time of a model impact sound was $4 \mathrm{~ms}$, and the decay time was 60,120 , or $250 \mathrm{~ms}$. The rise time and the decay time were defined here as the time required for $60 \mathrm{~dB}$ change in sound pressure level. Those stimuli were presented repeatedly as the test stimuli. The number of repetition was $1,2,4$, or 8 , and the time interval between two successive sounds was 100, 200, or $400 \mathrm{~ms}$. For the stimulus of eight bursts, however, the one with the time interval of $400 \mathrm{~ms}$ was not tested, because the total duration of the test stimulus attained at about $3 \mathrm{~s}$. If the time interval was longer than the duration of a single impact sound, each sound was completely separated (see Fig. 1, Type (A)), and if not, the envelope of successive bursts overlapped each other more or less (see Fig. 1, Type (B)).

Figure 2 shows a pair of stimuli for loudness adjustment test. The rise time and decay time of the comparison stimulus were $60 \mathrm{~ms}$, that is, its increasing and decreasing rate was $1000 \mathrm{~dB} / \mathrm{s}$. The duration of the steady part was $200 \mathrm{~ms}$, and this time was chosen as the duration required for a tone burst to have the same loudness as a continuous sound. These sounds were synthesized by amplitude modulation, and the carriers of test stimulus and comparison one were the same sinusoidal wave of $0.5,1$, or $2 \mathrm{kHz}$. The peak SPL of test stimulus was 80,90 , or $100 \mathrm{dBSPL}$ for $1 \mathrm{kHz}$ carrier and 90 dBSPL for 0.5 and $2 \mathrm{kHz}$ carriers.

This experiment was carried out in an anechoic room with a subject sitting $2 \mathrm{~m}$ apart from a loudspeaker. Figure 3 shows the schematic diagram of the experiment. The subjects were three males and two females who had some experiences in this kind of experiment. Their age ranged from 21 to 36 .

In a session of the experiment, 12 kinds of test stimuli, consisting of three levels of decay time and four levels of the number of repetition (nine kinds
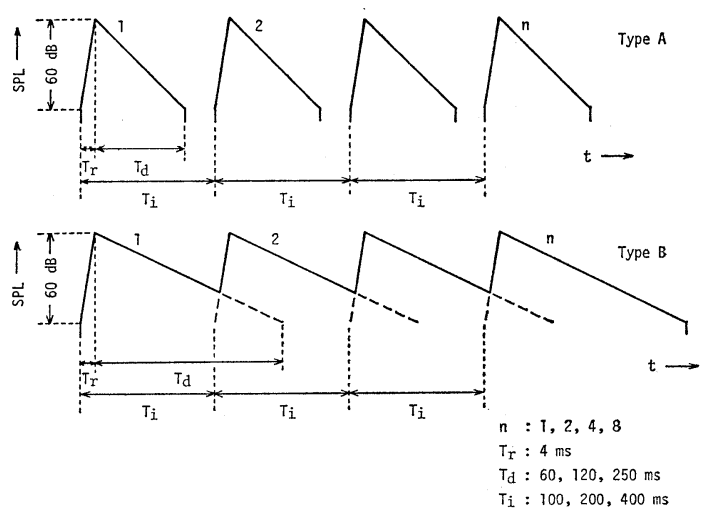

Fig. 1 Envelope of test stimulus used in the experiment.

If the time interval was longer than the duration of a single burst of impact sound, each burst was completely separated (Type A), and if not, the envelope of successive bursts overlapped each other more or less (Type B).

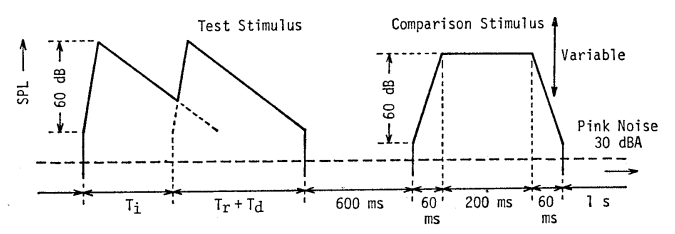

Fig. 2 Envelope of a pair of stimuli for the loudness comparison.

These stimuli were repeated until the subject completed his adjustment.

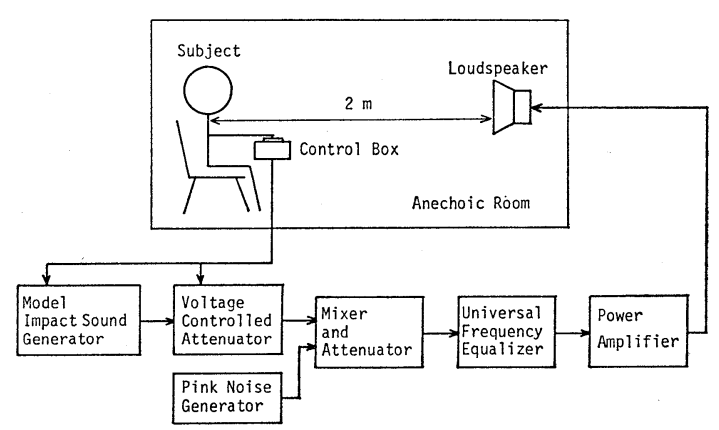

Fig. 3 Schematic diagram of the experiment for the loudness adjustment.

of test stimuli in the case of $400 \mathrm{~ms}$ interval), were presented in random order. The peak SPL and the interval were kept constant in a session, and five 


\section{KUMAGAI et al.: LOUDNESS OF REPEATED IMPACT SOUND}

trials were made for each condition.

The starting level of a comparison stimulus at the renewal condition was $20 \mathrm{~dB}$ below the level of test stimulus, and $30 \mathrm{dBA}$ pink noise was presented at the same time as a background noise in order to conceal the device noise and switching noise.

\subsection{Results}

Figures 4 and 5 show the results of this experiment, where PSE for loudness of repeated impact sound is expressed by peak SPL of the comparison stimulus. The results of the test stimuli with $1 \mathrm{kHz}$ carrier and peak SPL of 80,90 , and $100 \mathrm{~dB}$ are shown in Fig. 4, and those with 0.5 and $2 \mathrm{kHz}$ carrier and peak SPL of $90 \mathrm{~dB}$ are shown in Fig. 5,
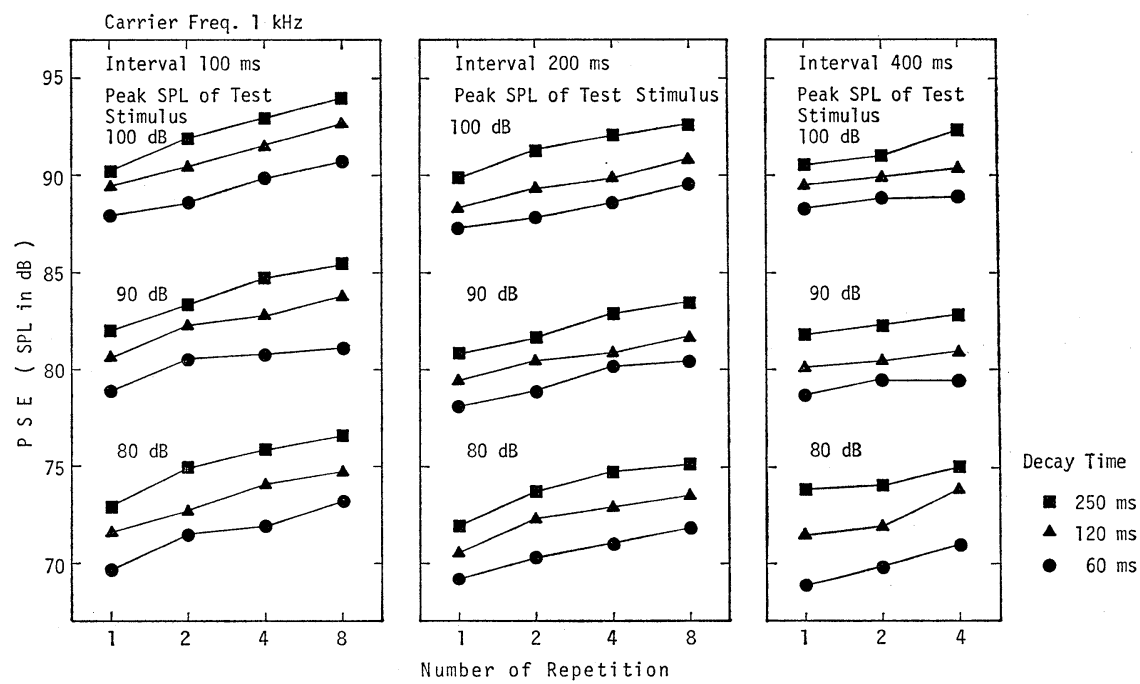

Fig. 4 Results of the experiment.

The average of the data for 5 subjects were plotted. Carrier frequency was $1 \mathrm{kHz}$.
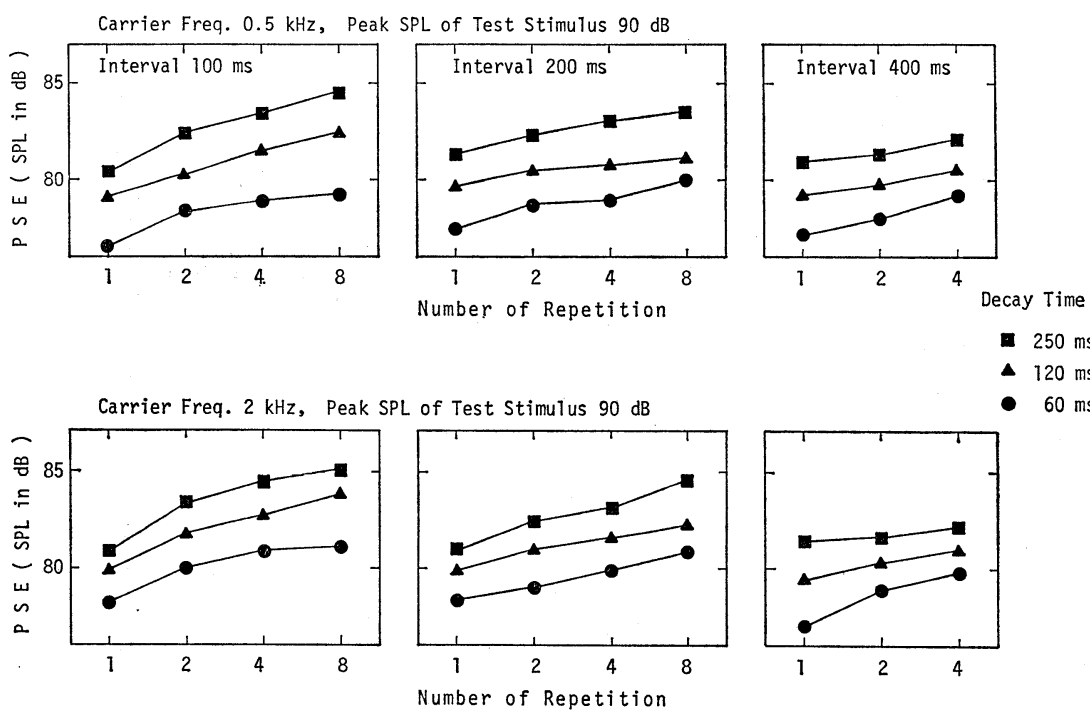

- $250 \mathrm{~ms}$

- $120 \mathrm{~ms}$

- $60 \mathrm{~ms}$

Fig. 5 Results of the experiment.

The average of the data for 5 subjects were plotted. Carrier frequency was 0.5 and $2 \mathrm{kHz}$. 
Table 1 Increment of PSE for doubling the number of repetition of impact sounds.

\begin{tabular}{lccc}
\hline $\begin{array}{l}\text { Carrier freq. }(\mathrm{kHz}) \\
\text { Peak SPL (dB) }\end{array}$ & $\begin{array}{c}1 \\
80,90, \text { and } 100\end{array}$ & $\begin{array}{c}0.5,1 \text {, and } 2 \\
90\end{array}$ \\
\hline Interval & $100(\mathrm{~ms})$ & $1.1(\mathrm{~dB})$ & $1.1(\mathrm{~dB})$ \\
& 200 & 0.9 & 0.8 \\
& 400 & 0.7 & 0.7 \\
\hline
\end{tabular}

where the average value for 5 subjects is plotted.

Though the interval of repeated sound was varied, the PSE for loudness of a single burst of impact sound is considered to be constant from an ideal viewpoint, but the mean value of $0.9 \mathrm{~dB}$ of fluctuation existed in this experiment.

The increment of PSE when the number of repetition was doubled was shown in Table 1. These are the mean values for $1 \mathrm{kHz}$ carrier and 80,90 , and $100 \mathrm{~dB}$ peak SPL, or $0.5,1$, and $2 \mathrm{kHz}$ carrier and $90 \mathrm{~dB}$ peak SPL.

\section{DISCUSSION}

As was seen from Figs. 4 and 5, when the interval between each burst is $100 \mathrm{~ms}$ and $200 \mathrm{~ms}$, the increment of loudness for doubling the number of repetition is larger, as a matter of course, than that with $400 \mathrm{~ms}$ interval. When the interval time is set to $100 \mathrm{~ms}$ or $200 \mathrm{~ms}$, the increment of PSE is not large and the PSE seems to approach to the satura- tion level as the number of repetition is increased from one to two, from two to four, from four to eight, though the repetition is always doubled in every case. This is quite natural, if we consider that there is a saturation characteristic in the loudness of sound along with the increase of its duration toward steady one. Besides, if the interval is 400 $\mathrm{ms}$, the increment of PSE is larger, when the number of repetition is increased from two to four, than that in the case when it is from one to two. This result may be attributable to its long interval. In other words, subjects may listen to individual stimulus as long as the number of repetition is a few, because the interval between successive bursts is relatively long. And if the number of repetition is increased further, subjects can no longer listen to each burst separately, and the loudness of the stimulus is felt to be increased as a whole. This is the reason why the larger increment of PSE is observed when the number of repetition is increased from two to four.

Figure 6 shows the experimental results for 1 $\mathrm{kHz}$ carrier which are the same data shown in Fig. 4. In this figure the PSE of loudness is shown as a function of the total energy level, $L_{\text {en }}$, of stimulus. ( $L_{\text {en }}$ equals to the single event exposure level.) As seen from this figure, when the peak level of stimulus is increased by $10 \mathrm{~dB}$, the PSE of loudness increases by $5 \mathrm{~dB}$, even if the total energy of the stimuli is the same. This result shows the same tendency as in

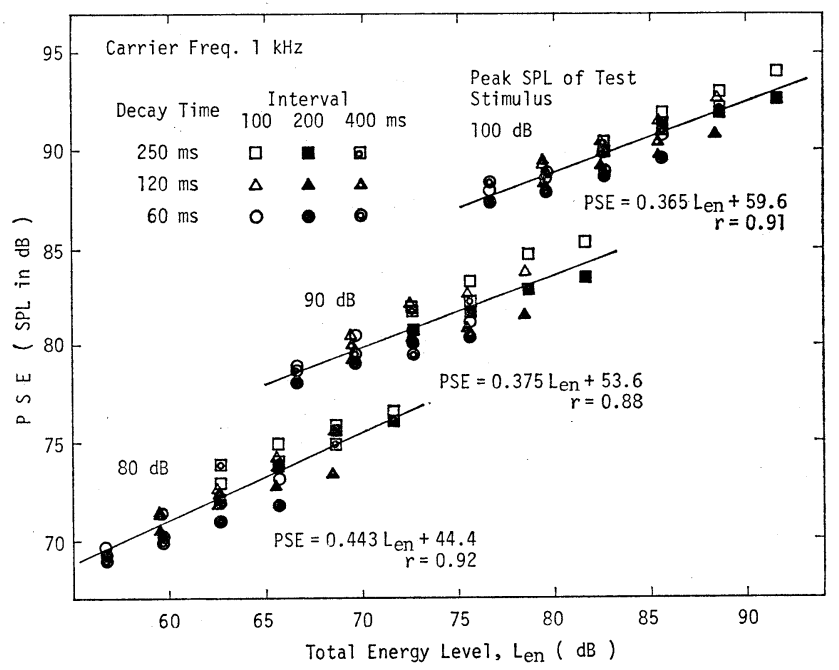

Fig. 6 Relation between calculated total energy level and PSE for $1 \mathrm{kHz}$ carrier, where data are the same as those in Fig. 4. 


\section{KUMAGAI et al.: LOUDNESS OF REPEATED IMPACT SOUND}

the case of a single burst of impact sound, ${ }^{1)}$ where the PSE of loudness is decided not only by the total energy but also by the peak SPL. The increment in PSE for $3 \mathrm{~dB}$ increment in total energy of stimulus (this increment in energy corresponds to doubling the number of repetition) is 1.1 to $1.3 \mathrm{~dB}$ as derived from the slope of the regression line. This value of increment is a little greater as compared with the result of a single burst of impact sound where the increment of PSE for the $3 \mathrm{~dB}$ increment of energy caused by lengthening the decay time of the stimulus was 0.8 to $0.9 \mathrm{~dB}$. This is explicable by the fact that the repetitive appearance of rapid rising parts causes some increase in loudness ${ }^{8,9)}$ in addition to that owing to the energy rule. Strictly speaking, the total energy of test stimulus shown in Fig. 1, Type (B) is not doubled, if the number of repetition is doubled, because of overlapping of decaying part of a burst with rising part of the next burst. However, the contribution of this overlapping to the total energy is less than $0.1 \mathrm{~dB}$.

In the experiments carried by Garrett ${ }^{5}$ ) and Carter $^{6,7)}$ the experimental conditions were different from ours, where the constant interval between two successive bursts was adopted. If our results are compared with theirs for 1 pps to 8 pps, the change of SPL required for keeping loudness constant was about $-3 \mathrm{~dB} /$ double repetition in the results obtained by Carter. It can simply be explained by the energy principle. Our results show smaller change, however, of about $1 \mathrm{~dB} /$ double repetition. This disagreement may be attributable to the difference in stimulus length between both experiments. Experimental result obtained by Garrett shows that the change in SPL required to keep loudness constant is about $-4 \mathrm{~dB} /$ double repetition for the burst of $1 \mathrm{~ms}$ duration. Furthermore it was shown in his result that the longer the burst duration was, the smaller the change in SPL required to keep loudness constant was. In our experiment, the duration of a single burst was chosen as about 20 to $80 \mathrm{~ms}$ (peak to $-20 \mathrm{~dB}$ ), while Carter used stimulus of only $1 \mathrm{~ms}$ duration.

As stated above, the loudness of a single burst of impact sound might be estimated by using squaring circuit with time constant of $125 \mathrm{~ms}$ as well as the loudness of quasi-steady sound. In the case of repetitive impact sound, however, it is assumed that a sound occurs before the sensation of previous sound is disappeared, so that the decaying part of the previous sound will sometimes overlap with the rising part of the next one. Furthermore, it may be natural to distinguish the time response of auditory system to rising part of stimulus from the one to the decaying part. To take these points into consideration as Port $^{10)}$ did, squaring circuit with two different time constants (rise and decay time constants) is used here. We kept the rise time constant being $125 \mathrm{~ms}$, while the decay time constant was changed in three different values to see the effect. Figure 7 shows the increase of SPL calculated under the condition that the rise time constant was $125 \mathrm{~ms}$, and the decay time constant was 125,200 , or $300 \mathrm{~ms}$ respectively. Open circles show the av-
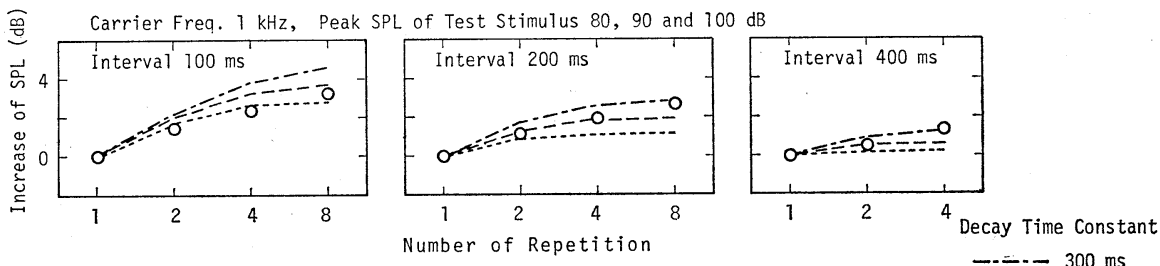

--.- $300 \mathrm{~ms}$

- - $-200 \mathrm{~ms}$
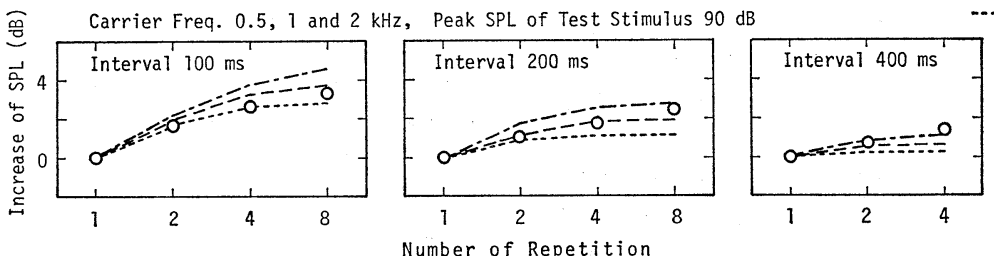

Fig. 7 The increase of SPL calculated under the condition that the rise time constant was $125 \mathrm{~ms}$, and the decay time constant was 125,200 , or $300 \mathrm{~ms}$ respectively. 
erage values of PSE from experimental results shown in Figs. 4 and 5, and three dashed lines show the calculated increment of peak indication caused by doubling the number of repetition. These calculated values vary, in general, with the decay time of test stimulus, even though it has the same time constant. In the figure the average values for three decay times are shown, however, since the difference in increment of PSE among three kinds of decay time was $0.5 \mathrm{~dB}$ at the maximum and $0.1 \mathrm{~dB}$ on an average in our experiment. The values are indicated with reference to the values for a single burst of test stimulus. According to Fig. 7, the short time constant seems to be applicable if the time interval between two successive bursts is short, while the long time constant is suitable for the loudness estimation if the interval is long. This tendency seems to agree with the fact that the impression of the bursts several pieces before is liable to dissipate because of the higher rate of bursts, and, on the contrary, the impression of bursts of lower rate remains longer.

Thus the suitable decay time constant is influenced by the time interval between successive bursts and it seems to be $200 \sim 300 \mathrm{~ms}$ as far as this experiment is concerned. This decay time constant is shorter than $700 \mathrm{~ms}$ proposed by Port, ${ }^{10)}$ and 700 1000 ms by Kado. ${ }^{11)}$ On the other hand, Miller ${ }^{12)}$ reported that $65 \mathrm{~ms}$ time interval was required for the sensation of loudness to decline to the threshold level, and it is $200 \sim 300 \mathrm{~ms}$ after Plomp. ${ }^{13)}$ The time constant of $200 \sim 300 \mathrm{~ms}$ obtained from our experiment is longer than those intervals. The conditions (duration of stimuli, carriers, sound pressure levels of stimulus presentation, the number of iteration, etc.) in their experiments are much different from ours, however, so that the results cannot simply be compared with each other.

\section{CONCLUSIONS}

As the results of the experiment on loudness of repeated impact sounds, in which the model impact sounds imitated from actual ones were repeated one to eight times at the interval of $100 \sim 400 \mathrm{~ms}$, the following was clarified:

(1) PSE of loudness of repeated impact sounds increases about $1 \mathrm{~dB}$ for doubling the number of repetition. This increase in PSE is greater for the shorter interval between successive bursts than for the longer ones. There is a tendency to show satura- tion as the number of repetition increases.

(2) The PSE of loudness does not obey the energy principle, but it increases around $5 \mathrm{~dB}$ for $10 \mathrm{~dB}$ increase in peak SPL of impact sounds even of the total sound energy is held constant. This tendency is about the same as in the case of a single impact sound. Furthermore, the increase in PSE for loudness is a little over $1 \mathrm{~dB}$ on an average for $3 \mathrm{~dB}$ increase in sound energy. This increase is greater by $0.2 \sim 0.5 \mathrm{~dB}$ than that caused by the increase of decay time in a single impact sound.

(3) The method of measuring the sound pressure level by the sound level meter, which has the squaring rectifier with the rise time constant of $125 \mathrm{~ms}$ and the decay time constant of $200 \sim 300 \mathrm{~ms}$, is appropriate for the measurement of the increase in loudness caused by the repetition of impact sounds.

\section{ACKNOWLEDGEMENTS}

The authors wish to thank Mr. H. Komatsu (now in Nippon Electric Co.) for his cooperation while he was under graduate student at Tohoku University. This work was supported by Grant-in-Aid of Scientific Research from the Ministry of Education, Culture and Science.

\section{REFERENCES}

1) M. Kumagai, M. Ebata, and T. Sone, "Effect of some physical parameters of impact sound on its loudness (A study on the loudness of impact sound. I)," J. Acoust. Soc. Jpn. (E) 2, 15-26 (1981).

2) M. Kumagai, M. Ebata, and T. Sone, "Comparison of loudness of impact sound with and without steady duration (A study on the loudness of impact sound. II)," J. Acoust. Soc. Jpn. (E) 3, 33-40 (1982).

3) M. Kumagai, M. Ebata, and T. Sone, "Loudness of impact sound with wide-band spectrum (A study on the loudness of impact sound. III)," J. Acoust. Soc. Jpn. (E) 3, 111-118 (1982).

4) W. R. Garner, "The loudness of repeated short tones," J. Acoust. Soc. Am. 20, 513-527 (1948).

5) R. M. Garrett, "Determination of the loudness of repeated pulses of noise," J. Sound Vib. 2, 42-52 (1965).

6) N. L. Carter, "Effect of repetition rate on the loudness of triangular transients," J. Acoust. Soc. Am. 37, 308-312 (1965).

7) N. L. Carter, "Effect of rise time and repetition rate on the loudness of acoustic transients," J. Sound Vib. 21, 227-239 (1972).

8) M. H. Goldstein, Jr. and N. Y.-S. Kiang, "Synchrony of neural activity in electric responses 


\section{KUMAGAI et al.: LOUDNESS OF REPEATED IMPACT SOUND}

evoked by transient acoustic stimuli," J. Acoust. Soc. Am. 30, 107-114 (1958).

9) J. M. Goldberg, H. O. Adrian, and F. D. Smith, "Response of neurons of the superior olivary complex of the cat to acoustic stimuli of long duration," J. Neurophysiol. 27, 706-749 (1964).

10) E. Port, "Zur Lautstäkeempfindung und Lautstäkemessung von pulsierenden Geräuschen,"
Acustica 13, 224-233 (1963).

11) H. Kado, "Loudness of fluctuating sound measured by discrimination test," J. Acoust. Soc. Jpn. 37, 274-283 (1981) (in Japanese).

12) G. A. Miller, "The perception of short burst of noise," J. Acoust. Soc. Am. 20, 160-170 (1948).

13) R. Plomp, "Rate of decay of auditory sensation," J. Acoust. Soc. Am. 36, 277-282 (1964). 